\title{
A Contrastive Analysis of the Verb Phrase in English and Engwo: Some Pedagogical Implications
}

\author{
Paul Mbufong \\ University of Douala, \\ Douala, Cameroon
}

\author{
Fontem A. Neba \\ University of Buea, \\ Buea, Cameroon
}

\author{
Abianji Emmanuel \\ Government High School Ekona, \\ Ekona, Cameroon
}

\begin{abstract}
This study sets out to perform a contrastive analysis of the verb phrase in English and Engwo. This is because it is suspected that the differences between the components of the verb phrase in both languages may account for some of the errors that native speakers of Engwo learning English as a second language commit. Special attention was to verb phrase components and their placement in verb phrase structure. Sample verb phrases were collected from recorded speeches, interviews, observations, and the researchers' knowledge of both languages. The data were then analyzed. The results of the research suggest that the components of the verb phrase in both languages pose few problems but their placement in verb phrase structure and the modifications they undergo account for many of the numerous errors that native speakers of Engwo make when learning English as a second language.
\end{abstract}

Keywords: contrastive analysis, verb phrase, pedagogy

\section{Introduction}

The desire to learn English either as a second or foreign language is increasing in Cameroon. Cameroon is a country where English is learned as a second language by English speaking Cameroonians (Anglophones) and as a foreign language by French speaking Cameroonians (Francophones). The language is given a high coefficient in class and certificate examinations. It is also given a high premium in professional examinations.

There is an increasing effort made by learners to avoid errors in the target language. Despite these efforts, their utterances in the target language are not error free. The errors are numerous and varied. A study of these errors reveals that many of them result from the negative transfer of features from the learner's mother tongue to the target language while others result from the learner's attempt to reproduce the rules of the target language he or she has formulated or memorized.

Contrastive analysis, a term coined by Lado (1957), seeks to establish the similarities and differences between languages with the assumption that the areas of similarities will be easier to study in a target language while differences will pose learning difficulties (Bouton, 1970; Gradman, 1971; James, 1976, 1980).

This research seeks to perform a contrastive analysis of the verb phrase in English and Engwo. It intends to

Paul Mbufong, lecturer, Department of English and Foreign Languages, University of Douala.

Fontem A. Neba, lecturer, Department of English, University of Buea.

Abianji Emmanuel, lecturer, Department of English, Government High School Ekona. 
compare and contrast verb phrases in both languages, and to attempt to establish the areas which might pose problems to learners of English as a second language with Engwo as a first language.

Engwo is the native language spoken by the Ngwo people found in Njikwa Sub-Division in the Northwest Region of Cameroon. It is one of the 279 native languages spoken in Cameroon (Tanda, 2006).

Engwo has co-existed with English for a long time. Engwo also makes use of English words that have been borrowed and adjusted phonologically (see Example (1)).

$\begin{array}{cc}\text { Example (1) Pen } & \underline{\varepsilon p} \underline{\varepsilon} n \\ \text { Ball } & \text { boro } \\ \text { Towel } & \text { tawet }\end{array}$

The relationship between both languages can be felt even in the educational milieu. Ngwo students who are in the same school, at the same level of education and who are taught in school using English often revise or discuss their school subjects among themselves in Engwo though they will have to write the subjects in English.

It is for this reason that the present research seeks to find out if the similarities and differences between the verb phrase components in both languages can account for the numerous errors involving the verb phrase that native Engwo speakers make in learning English as a second language.

The study is very necessary when one looks at the fact that very little has been written about Engwo (Ntembe, 1987; Abianji, 1999).

\section{Materials and Method}

The main method of data collection is a form similar in nature to the Grammar Translation Method that was propounded by Johann Seidenstucker, Karl Plotz, H. S. Ollendorf, and John Meidinger in that "it approaches the language first through detailed analysis of its grammar rules followed by application of this knowledge to the task of translating sentences and texts into and out of the target language" (as cited in Richards \& Rodgers, 1995). This research is therefore based on a series of verb phrases that have been given in Engwo, and then, translated into English and vice versa.

Because no previous attempt has been made to classify the components of the verb phrase in Engwo, the components have thus been classified following the English classification. The components in Engwo are therefore based on the English components to see how they can be realized in Engwo. The other components in Engwo that do not exist in English have also been considered. Data were then collected in both languages, placed side by side and contrasted.

\section{Contrastive Analysis and Discussion of Results}

This involves comparing and contrasting verb phrases in English and Engwo and predicting the errors that are likely to occur.

\section{Verb Phrases Containing Modal Verbs}

This involves verb phrases that make use of English modals such as may, might, can, could, will, would, shall, etc. (see Example (2)). 


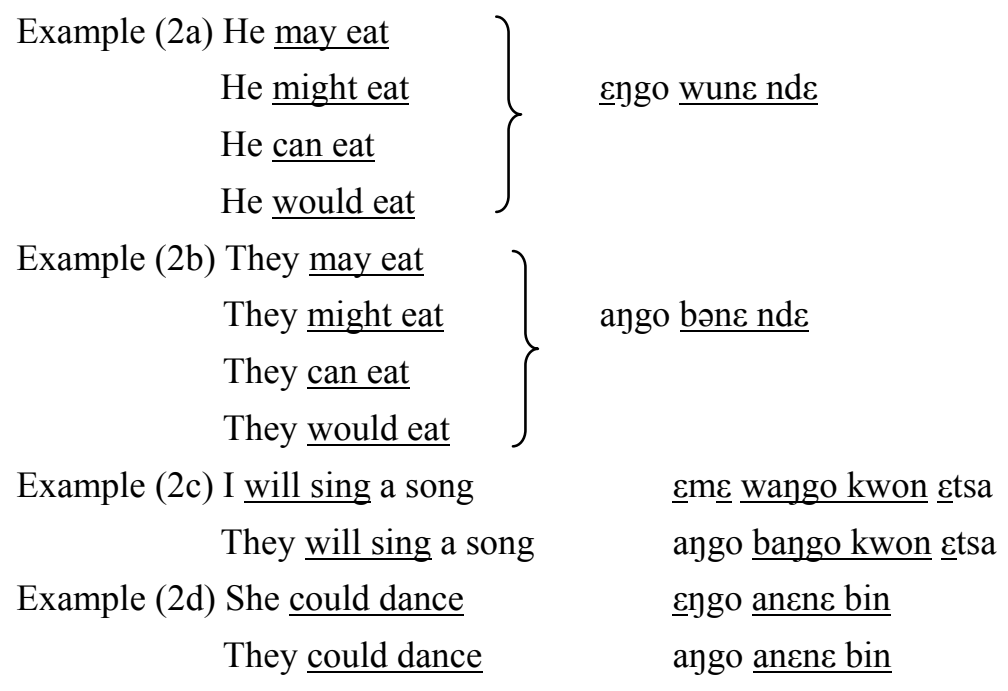

Of the auxiliaries in English, may, might, would, will, and shall express the possibility of the action of the verb taking place now or in the future. Could is used to show the possibility of the action of the verb in the past. As can be seen from the data above, Engwo has only two forms which can be used for may, might, can, and would which are wun $\underline{\varepsilon}$ (see Example (2a)) if the subject is singular and bən $\underline{\varepsilon}$ (see Example (2b)) if the subject is plural. Equally, will vary depending on whether the subject with which it is used is singular or plural. If the subject is singular, wango (see Example (2c)) is used, and if the subject is plural, bango (see Example (2c)) is used. Unlike the other auxiliaries that vary when used with singular or plural subjects, could remains the same angn $\underline{\varepsilon}$ (see Example (2d)) whether it is used in the singular or in the plural.

From the above data, one can predict that there may be semantic errors resulting from the misuse of modals since there are more modals in English than in Engwo. The native Engwo speakers may not be able to know the difference between the following sentences since they mean the same thing in Engwo (see Example (3)).

Example (3) They look at me

$$
\left.\begin{array}{l}
\text { They may look at me } \\
\text { They might look at me } \\
\text { They would look at me }
\end{array}\right\} \quad \text { ango bən } \underline{\varepsilon} \text { k } \underline{\varepsilon} \text { d } \underline{\varepsilon} \text { angu }
$$

\section{Verb Phrases Containing Finite Verbs/Tenses}

The finite form of a verb is used to show agreement with the subject and to show agreement with the subject and to indicate tense. It is the most widely used form of the verb.

Example (4) English
\[ \begin{array}{l}\text { Write } \\ \text { I am writing English } \\ \text { We are writing English } \\ \text { She writes English } \\ \text { They write English } \\ \text { I } \underline{\text { ate rice }}\end{array} \]

Engwo

$\underline{\eta \underline{w}} \underline{\underline{r} \underline{\varepsilon}}$

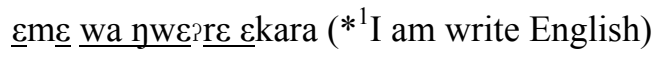

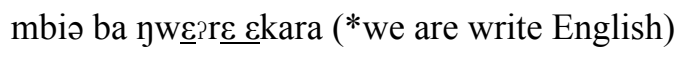

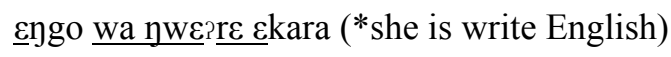

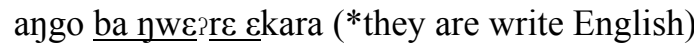

$\underline{\varepsilon} \underline{\varepsilon} \underline{\text { aa nd} \varepsilon}$ ali $\underline{1} \mathrm{i}$ (*I [past tense marker] eat rice)

\footnotetext{
1 The star indicates that the structure is ungrammatical in standard English.
} 
We ate rice

We will speak to him

I will speak to him mbiə aa nd $\underline{\text { ali } \int i ~(* w e ~[p a s t ~ t e n s e ~ m a r k e r] ~ e a t ~ r i c e) ~}$ mbiə ba gama bo ango (we will speak [pl] to him) $\underline{\varepsilon} \underline{\varepsilon}$ wa ga bo $\operatorname{ggo}$ (I will speak [sg] to him)

The sentences in Example (4) involve verb phrases that contain finite verbs/tenses in English and Engwo. They have been carefully selected to show the various aspects of the verb phrase in both languages. When a verb is used in the infinitive in English, there is no problem to realize it in Engwo. Problems arise when the verb is conjugated. This is because tenses are realized in Engwo through the use of auxiliary verbs which most often vary depending on whether the subjects with which they are used are singular or plural. In the present continuous tense, we see that "is" in Engwo is realized as "wa" and "are" is realized as "ba" and the verb that comes after any of

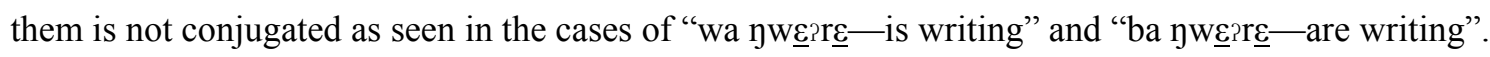

With regards to the simple present tense in English, the verb is inflected for tense by the addition of an " $\mathrm{s}$ " to the verb if the subject is singular except when " $\mathrm{I}$ " is used as the subject. No "s" is added if the subject is singular. In Engwo, this tense is realized in the same way like the present continuous tense as seen in Example (5).

\begin{tabular}{|c|c|}
\hline Example (5) English & Engwo \\
\hline She writes & 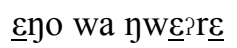 \\
\hline They write & 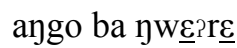 \\
\hline
\end{tabular}

Some verbs are inflected in Engwo but this is for plurality as seen in the examples involving speak (see Example (6)).
Example (6) We will speak mbio ba gama (gama = speak [plural]) I will speak $\quad \underline{\varepsilon} \underline{\varepsilon}$ wa ga $(\mathrm{ga}=\operatorname{speak}$ [singular])

We see here that if the subject is singular "I", "ga = speak" which is not inflected for plurality is used. If the subject is plural "we", "gama = speak" which is inflected for plurality id used. In the case of "ate" where the verb is conjugated in the past tense, the tense is realized through the position of "aa" (a tense marker) in front of the verb, and then, a verb in the infinitive.

From the data, it can be predicted that native Engwo speakers may tend to use an auxiliary followed by a verb in the infinitive, since it is a structure common in their language, there by producing asyntactic English sentences as shown in Example (7):
Example (7) They have eat aygo $\int \mathrm{i} \operatorname{nd} \underline{\varepsilon}\left(\int \mathrm{i}\right.$ nd $\underline{\varepsilon}=$ have eat $)$
She has go
Égo $\int \mathrm{i}$ ggo $\left(\int \mathrm{i}\right.$ ggo $=$ has go $)$

They may tend to add the tense marker "s" or "es" to a verb thinking they are inflecting the verb for plurality since some verbs are inflected in Ėgwo for plurality as in Example (8):
Example (8) They have gone aygo $\int \mathrm{i}$ jgoro $\left(\int \mathrm{i}\right.$ jgoro $=$ have goes $) *$ They goes
She has gone $\quad$ Engo Ji ggo $\left(\int \mathrm{i}\right.$ jgo $=$ has go $) *$ She has go

\section{Reduplication of Verbs}

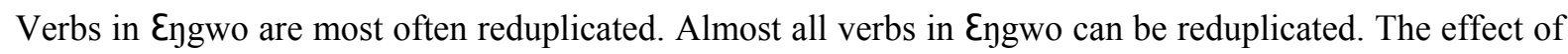
reduplication will depend on the intension of the speaker and what the hearer makes of the situation. This process is done for different reasons. It can be for encouragement, or to minimize the stress involved in the execution of the action of the verb. It can be for emphasis or to communicate the effect of the English "just". Reduplication is 
at times used to show the type of terrain one is moving on. Verbs may be reduplicated more than twice but this is most often to show that the action of the verb took place over a long period of time.

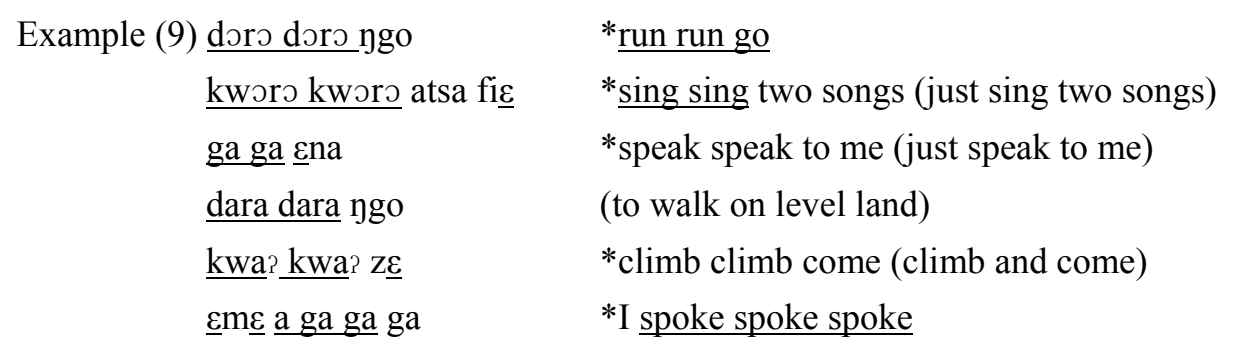

The sentences in Example (9) have been used to show the reduplication of verbs. The verbs "dara dara" and "kwa? kwa?" are used to show the type of terrain on which one is moving but "dara dara" has not got an English equivalent as "walk" cannot sufficiently describe it. Together with the other verbs they are reduplicated to achieve any of the other reasons already stated.

\section{Borrowed Auxiliaries}

Auxiliary verbs have been borrowed from English to Engwo to be used in expressions needing auxiliaries that Engwo has no auxiliaries for. The main auxiliary that has been borrowed from English is must which is pronounced in Engwo [ $\left.\mathrm{m} \wedge \int \mathrm{i}\right]$. "Get" is a verb that has been borrowed from English but is used as an auxiliary verb in Engwo to stand for either "has to" or "have to" as seen in Example (10):
Example (10) You must eat ngwo wa $\mathrm{m} \wedge \int \mathrm{i}$ nd $\underline{\varepsilon}$ (*You have to must eat)
Joe has to go

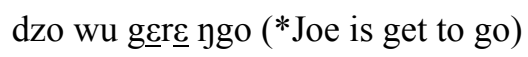
They have to come

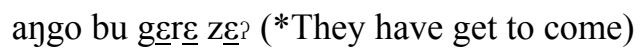

From the above data, it can be predicted that "must" will pose no problem to the learners since it is borrowed with its meaning in English, but "get" will pose a problem as the learners may tend to use it as an auxiliary, thereby producing asyntactic sentences as shown in Example (11):
Example (11) Engwo equivalent
Correct English form
*You get to do the work

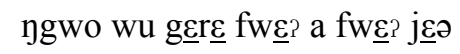
You have to do the work

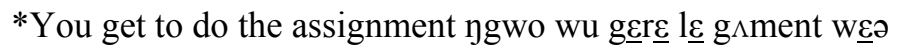
You have to do the assignment

\section{Conclusions: Pedagogical Implications}

The above study focused on the differences that exist between the components of the verb phrase in English and Engwo to predict the errors that are likely to be committed by a native Engwo speaker learning English as a second language. Using sample verb phrases containing modal auxiliaries, finite verbs, and borrowed auxiliaries from English to Engwo and reduplication of verbs in Engwo, the study was able to relate the verb phrases to the likely errors that a native Engwo speaker will commit when learning English as a second language. It is worth noting here that these are only predictions that are likely to occur. Some or all may occur with different learners. None of the errors may even be found with some of the learners since language study differs from learner to learner.

A teacher of English to these Engwo native speakers should be expected to meet some of these errors and so should be better prepared to overcome them. Contrastive analysis can be used to predict the hierarchy of difficulty in learning English as a second language to a native Engwo speaker. This will go a long way to help structure the English language lesson, beginning with the areas of similarities to the areas of differences. Even the 
difficult areas can be structured from the less difficult to the most difficult to facilitate learning by the learners. These and other suggestions could help to reduce the learners' difficulties.

\section{References}

Abianji, E. (1999). The noun phrase: A contrastive study between Ngwo and English (Unpublished dissertation for D.I.P.E.S. II. University of Yaounde 1, E.N.S. Yaounde).

Bouton, L. F. (1970). The problem of equivalence in contrastive analysis. IRAL, 14(2), 143-163.

Gradman, H. (1971). The limitations of CA predictions (PCCLLU papers, University of Hawaï).

James, C. (1976). The exculpation of contrastive linguistics. In G. Nicke (Ed.), Papers in contrastive linguistics (pp. 53-68). Cambridge: Cambridge University Press.

James, C. (1980). Contrastive analysis. London: Longman.

Lado, R. (1957). Linguistics across cultures. Ann Arbor: University of Michigan Press.

Ntembe, P. (1987). Borrowing into the Ngwo language (Unpublished dissertation for the undergraduate diploma, University of Yaounde 1, E.N.S. Annex Bambili).

Richards, C., \& Rodgers, S. (1995). Approaches and methods in language teaching: A descriptive analysis. Cambridge: Cambridge University Press.

Tanda, V. (2006). Sociolinguistic aspects of language loss: A case study of the language situation of Cameroon. In E. N. Chia, K. I. Tala, \& V. A. Tanda (Eds.), Perspectives on language study and literature in Cameroon. Limbe: ANUCAM. 